\title{
E-DEVLET ENTEGRASYONUNDA KAMU VE ÖZEL SEKTÖR İŞ SÜREÇ YÖNETIMİ UYGULAMALARININ YERİ VE ÖNEMİ: GPM VE BPMN' E DERLEYİCI BİR BAKIŞ AÇISI
}

\author{
THE ROLE AND IMPORTANCE OF PUBLIC AND PRIVATE SECTOR BUSINESS \\ PROCESS MANAGEMENT APPLICATIONS IN E-GOVERNMENT INTEGRATION: A \\ COMPREHENSIVE PERSPECTIVE TO GPM AND BPMN
}

\author{
Özel SEBETCI ${ }^{1}$ - Muhammet ÖZDAŞ ${ }^{2}$
}

\section{$\ddot{\mathbf{O} z}$}

E-devlet sistemi devlet dairesi çalışmalarında önemli bir rol oynamaktadır, ancak geliştirme sürecinde, ortak işlevlerin tekrar tekrar geliştirilmesi, çeşitli kurumların ihtiyaçlarının genel bir model olmadığı için karşılanamaması, süreç yönetiminde uygulamanın zorlaştırıldığı ve farklı sistemlerin bağımsızlığı gibi bazı sorunlar vardır. Bu problemler, gelişme sürecini ciddi şekilde engellemekte, geliştirme maliyetini arttırmakta ve gözden kaçan bilgiler ile sonuçlanabilmektedir. Bu sorunları çözmek için, bu makale e-devlet odaklı bir BPM GPM - BPMN platformları tasarımını ve uygulama sürecini tanıtmaktadır. Hızlı bir gelişme sağlamak için analiz ve soyutlama yaparak, ortak sistemlerin temel özelliklerini ortaya çıarmakta ve yapılandırılabilir işlevlere dönüştürülmesi önerilmektedir. Güçlü form oluşturucusu olarak BPMN tabanlı iş akışı motoru, geliştirme ve dağıtım sürecini önemli ölçüde basitleştirebilir, sistemler arası bilgi alışverişini destekleyebilir ve geliştirme verimliliğini artırabilir sonucuna varılmaktadır.

Anahtar Kelimeler: e-Devlet, Bpm, Gpm, Bpmn

\begin{abstract}
The e-government system plays an important role in the work of government departments, but there are some problems in the development process, such as the development of common functions over and over, the needs of various institutions not being met because it is not a general model, the implementation of process management is difficult, and the independence of different systems. These problems seriously hinder the development process, increase the development cost, and may result in overlooked information. To solve these problems, this article introduces the design and implementation process of an e-government-oriented BPM - GPM - BPMN platform. In order to achieve rapid development, it is recommended that analysis and abstraction reveal the basic features of common systems and transform them into configurable functions. As a powerful form builder, the BPMN-based workflow engine can significantly simplify the development and deployment process, support inter-system information exchange, and improve development efficiency.
\end{abstract}

Keywords: e-Government, Bpm, Gpm, Bpmn

\footnotetext{
${ }^{1}$ Dr.Öğr.Üyesi, Adnana Menderes Üniversitesi, osebetci@adu.edu.tr, Orcid: 0000-0002-2996-0270

${ }^{2}$ T.C. Cumhurbaşkanlı ̆ Strateji ve Bütçe Başkanlığ
}

Makale Türü: Araştırma Makalesi - Geliş Tarihi: 19-12-2019 - Kabul Tarihi: 21-05-2020

DOI:10.17755/esosder.661545

Atıf için: Elektronik Sosyal Bilimler Dergisi, 2020; 19(75):1393-1406 


\section{Giriş}

Toplumun gelişen zorlukları, kademeli olarak kamu kesiminin bu sorunları çözme kapasitesini aşıyor. Bu zorluklarla başa çıkabilmek için bütçe yetersizliği olan hükümetlerin operasyonlarını ve hizmet sağlama modellerini dönüştürmek ve iyileştirmek için yenilikçi yollar araması gerekiyor. Politikalar yüzünden dönüşüm birçok durumda içeriden dışarıya doğru başlasa da (BİT'ler yoluyla yeniden yapılanmaya odaklanırken), dışarıdan içeriye dönüşmek için dış BİT gelişmelerinin devletler tarafından aktifleştirilmesi belirli bir inisiyatif gerektiriyor. Kamu ve özel sektör paydaşlarını birbirine bağlamak için BİT 'deki inovasyonel platformlardaki gelişmeler ümit vericidir (Klievink, Bharosa ve Tan, 2016).

Kamu kurumunun örgütlenmesinde, faaliyetlerinde ve yönetişimindeki değişiklikler açısından hükümetin dönüşümü bir süredir elektronik devlet ve kamu sektörü reformunda önemli bir konu olmuştur (Borins, 2014; Janowski, 2015). Bu tür bir değişimin amac1, en azından kamu harcamalarında tasarruf yapmak, kamu hizmetlerini iyileştirmek (kalite ve etkinlik bakımından) ve devletin faaliyetlerini daha verimli kılmaktır (Pollitt ve Bouckaert, 2004). Devletin dönüşümü hükümeti dijitalleştirmenin ötesine geçer ve kamu sektörünü daha etkili hale getirmekle ilgili olur (Van Veenstra, Klievink, \& Janssen, 2011).

Bütçe azlığı olan devlet kurumlarının değişmesi beklendiğinden devlet kurumlarının iç içe geçtiği çevreyi etkileyen iç süreçleri iyileştirmeye ve maliyetleri düşürmeye odaklanmak yerine, başkalarının yeniliklerinden yararlanmayı düşünmeli ve bu yenilikleri dönüşüm amaçlarını yerine getirmek için kullanmalı ve yönlendirmeye çalışmalıdırlar (Weerakkody ve Dhillon, 2008). Başka bir deyişle: hükümetler, başkalarının işbirliğiyle, operasyonlarını dönüştürmek için devlet kurumları tarafından dışsal gelişmelerin kullanıldığı, farklı bir dönüşüm inisiyatifleri sınıfı oluşturan dıştan içe dönüşüm yapmayı da düşünmelidir (Janssen ve Estevez, 2013). Ancak bilişim altyapısına ilişkin zorluklar yüzünden standart iş raporlaması (SBR) gibi durumlarda, paydaşlar modüler ve esnek bir seçim yapmıştır. $\mathrm{Bu}$, devlet kurumları için önemli bir stratejik seçenektir. Çünkü bilişim altyapısı gelecekte daha fazla raporlama zincirine yani inovasyonun dönüştürücü karakterini arttırması beklenir.

SBR platformu, genişletilebilir İş Raporlama Dili (XBRL) olarak bilinen XML tabanlı bir dilde yapılan son gelişmeler ve uygulamalarla sağlanmaktadır. Bu seçenek, ayrıntılı sınıflandırmanın genişletilmesine izin veren XBRL kullanımıyla da korunmaktadır. Bunun, SBR bilgi altyapısının süreçleri, verileri ve teknoloji katmanları üzerinde etkisi vardır. Süreçler, işletmeler ve devlet kurumları (ve tersi) arasında mesajların (XBRL'de) doğrulanması ve aktarılması için aktif olan otomatikleştirilmiş aktivitelere atıfta bulunmaktadır. $\mathrm{Bu}$ süreçler İş Süreci Modelleme Notasyonu (BPMN) kullanılarak modellenmiştir. $\mathrm{Bu}$ motor, mimarinin teknoloji katmanını temsil eder ve BPMN modelini, işlemlerin otomatik olarak ele alınması için web hizmetlerini uyandırmak için "script" olarak kullanır (örneğin, gönderenin doğrulanması ve ayrıntılı sınıflandırmaya karşı doğrulama).

Uluslararası Ticaret yapısının özellikleri nedeniyle, böyle bir koordineli yaklaşım orada mümkün değildir. Çok çeşitli sistem ve yaklaşımlara uyum sağlanmasına ihtiyaç vardır. $\mathrm{Bu}$ nedenle, vurgu, farklı iş modellerine sahip, ancak birleşik arabirimler tarafından anlamsal olarak bağlanan farklı kullanılabilir. Böyle bir federe sistemi uygulamak için bir ön koşul, etkileşim için kullanılan verileri tanımlamak, sunmak ve keşfetmek için standart ve tek biçimli bir araç kullanmaktır. Bu, veri paylaşımı standartlarının gerekli olduğu anlamına gelir. Sonuç olarak, BT çözüm sağlayıcılarının kararlaştırdıkları standartlar (UN / CEFACT (The United Nations Centre for Trade Facilitation and Electronic Business), ebXML(Electronic Business XML Initiative)) ile ticari elektronik belgeler için bir XML mimarisi geliştirmiştir. $\mathrm{Bu}$ standartlar, anlamsal ve sözdizimsel birlikte çalışabilirliği teşvik eder ve yetkililerin bu 
çeşitli çözümleri sorgulamaları ve ihtiyaç duydukları verileri toplamaları için kapsamlı görünürlük çözümlerini destekler (Klievink, Bharosa ve Tan, 2016).

Çalışmada, bu tip problemleri çözümlemek yönünde özellikle kamu içi ve kamu-özel platformları konuşturmak için kullanılabilecek İş Süreç Yönetimi (GPM - BPMN) ile ilgili güncel kavramlarının açıklaması hedeflenmiştir. Bununla birlikte, kamu-özel platformlarını bir dönüşüm çabası, ilgili (politika) araçlarının bir parçası olarak kullanmaya ya da platformlar aracılığıyla dönüşümün sunduğu kademeli çok seviyeli zorluklarla başa çıkmaya ilişkin çok fazla araştırma yoktur. Ayrıca bu makale, konuyla ilgili bilgi boşluklarını ele almaktadır. Dolayısıyla işletmeler ve devlet kurumları arasındaki standart iş raporları ve bilgi platformlarının önemine değinilmesi hedeflenmiştir. Dünyada, platformlar kamu ve özel kuruluşlar tarafından ortaklaşa geliştirilmekte ve kullanılmaktadır. Bu girişimler, devlet kurumlarının kamu-özel platformlarının gelişimini, işletme-devlet etkileşimlerini dönüştürürken ve daha genel olarak kolektif çıkarlara ve kamu değerine hizmet ederken kendi çıkarlarını takip etmelerini sağlayacak şekilde yönlendirebilir ve şekillendirebilir.

\section{E Devlet, Kurumsal Mimari, İş Süreç Yönetimi ve Devlet Süreç Yönetimi}

Bir e-devlet sistemi, hükümet bilgi ve hizmetlerine paydaş erişiminde daha fazla kolaylık sağlayan yeni bir dönem sunan bir dizi hükümet süreci etrafında ifade edilmektedir. Bununla birlikte, e-devlet uygulamalarına ilişkin çalışmalar, çoğu devlet kurumunun destekleyici süreçlerini dönüştürmediğini ve iyileştirmediğini göstermiştir. Web tabanlı bu portallar destekleyici devlet süreçlerinden uzak kaldığ 1 için bu hazırlanan portallar ile beklenen vaatler arasında büyük bir boşluğa yol açmıştır. Dolayısıyla yasal süreçlere göre verimli devlet süreçleri tasarlamak için Hükümet Süreç Yönetimi yaşam döngüsünü, özellikle tasarım aşamasını göz önünde bulundurmak gerekliliği ortaya çıkmıştır. Aslında, hükümet süreçleri için, tüm tasarım seçimleri yasal metinlerle desteklenmelidir. Bunu yapmak için, geliştirilen yaklaşım, yasal tasarım ve operasyonel tasarım olmak üzere iki ana düzeyde ifade edilir. Temel amaç, ortak devlet süreçleri modelleri, açık yasal gerekliliklerin temsili ve ortak alan kavramları ve hizmetleri üretmek olmalıdır (Cherouana, Mahdaoui, ve Khadraoui, 2017).

Dünyanın dört bir yanındaki hükümetler, kamu hizmeti sunumunu modernize ve optimize etmek için bir e-devlet beklentisini memnuniyetle karşıladılar. Ancak, kamu hizmetlerinin elektronik ortamda başarılı bir şekilde sunulması için aşılması gereken hala birkaç kısıtlama vardır. Organizasyon, yönetim ve teknoloji gelişmelerini birleştirmek için daha büyük bir çerçeve gerekmektedir. Kamu hizmetini yaratacak ya da kullanacak paydaşları belirler, hizmeti tanımlar ve modeller, e-devlet hizmetini uygular ve değerlendirir. Hizmeti, iyi tanımlanmış, esnek ve yeniden kullanılabilir bir grafiksel şekilde modellemek ve ilgili tüm paydaşların organizasyonel birlikte çalışabilirliğini sağlamak için iş akışı düzenleri benimsenmelidir. Web hizmetleri, e-devlet hizmetini uygun maliyetli ve teknik olarak birlikte çalışabilir bir çözüm olarak uygulamak için kullanılır (Ntaliani, Costopoulou, Karetsos, Tambouris ve Tarabanis, 2010).

Ulusal bir mimari bilgi altyapısı oluşturulması dünya genelinde pek çok ülkede öncelikli hedeflerden biri haline gelmiştir (Shin, 2007). Ülkemizde de 2000'li yılların başlarında Başbakanlık tarafindan bu alana yönelik raporlar oluşturulmuştur (Başbakanlık, 1999; Başbakanlık, 2001). Kurumsal mimariler devlet açısından düşünüldüğünde, mimarilerin kurumsal seviyeyle sınırlı tutulmadan ulusal ve kurumsal olmak üzere iki ayrı seviyede tasarlanması gerekecektir. Bu açıdan bakıldığında, birlikte çalışabilirlik e-devlet kurumsal mimarilerinin en temel unsurlarından birisi olarak öne çıkmaktadır. Kamu penceresinden bakıldığında birlikte çalışabilirlik, organizasyonların bilgi ve diğer kaynakları ihtiyaç duyan paydaşlara hızlı ve maliyet etkin şekilde paylaşabilmesini sağlayan unsurlardır (Pardo ve Burke, 2009). e-Devlet alanında ileri düzeydeki ülkelerin tamamında kamu kurumları ve 
hizmetleri arasında birlikte çalışabilirliğe ilişkin olarak standart ve rehberler yayımlanmıştır. İngiltere'de e-Devlet Birimi tarafından ilk sürümü 2000 yılında yayınlanmış olan e-Devlet Birlikte Çalışabilirlik Çerçevesi (e-GIF) 2005 yılında da güncellenmiş olup (Guijarro, 2007) sonrasında yerini daha hizmet odaklı bir bakış açısına sahip olan Hizmet Kılavuzuna bırakmıştır (U.K. Service Manual, 2019). İngiltere'nin birlikte çalışabilirlik çerçevesi oluşturmaya yönelik çalışmaları döneminin ilk örneği olup kısa bir süre sonra çok sayıda ülke benzer adımları atmıştır (Lisboa ve Soares, 2014). Fransa'da 2002 yılında yayınlanan ADAE çerçevesi ve Almanya'da 2003 yılında yayınlanan SAGA çerçevesi de buna örnektir (Guijarro, 2007). Ülkemizde ise 2003 yılında mülga Devlet Planlama Teşkilatı tarafından Birlikte Çalışabilirlik Esasları Rehberinin ilk sürümü 2005 yılında yayımlanmış olup son sürüm olan 2.1 sürümü ise Devlet Planlama Teşkilatının yerini alan Kalkınma Bakanlığı tarafindan 2012 yılında yayımlanmıştır (Kalkınma Bakanlığı, 2012). Bahsi geçen rehber ve çerçevelerden hemen hiçbirisi günümüzde güncellenmemektedir. Bunun iki önemli sebebi olduğu düşünülmektedir. Birincisi, günümüzde birlikte çalışabilirlik daha geniş bir çerçevede ele alınmakta olup teknik hususlar artık bütün içerisinde ufak bir parçayı teşkil etmektedir. İkinci sebep ise bilişim alanındaki standartların olgunlaşmasıyla birlikte ürün ve hizmet seviyesinde standartlaşmanın daha kolay temin edilebiliyor olmasıdır. Teknik birlikte çalışabilirlik günümüzde yerini topyekün süreç yönetimine ve bütüncül hizmet sunumuna bırakmaktadır.

ABD'de diğer ülkelerin aksine standartların e-devlet projelendirme ekipleri tarafından münferiden belirlendiği, ancak bütün kurumlarda tek bir kurumsal mimari yapısının zorunlu tutulduğu bir yapılanma benimsenmiştir. Bu yapının temeli 1996 yılında yayımlanan ClingerCohen Kanununa dayanmaktadır. Kanunun bir sonucu olarak 1999 y1lında Federal Kurumsal Mimari Çerçevesi oluşturulmuş olup bu çerçeve yaygın olarak kullanılan Zachman Çerçevesi temel alınarak geliştirilmiştir (Guijarro, 2007). Avrupa Birliği ülkelerindeki hedef değişiminin bir benzerini ABD'de de görmek mümkündür. Federal Kurumsal Mimari Çerçevesi tamamlanamamış ve Yönetim ve Bütçe Ofisi 2002 yilında Federal Kurumsal Mimari ile başlattığı çalışmaları birlikte çalışabilirliği daha geniş bir çerçevede ele alacak şekilde yürütmeye devam etmiştir (Bellman ve Rausch, 2004).

Genelde kamu hizmetleri, idari bilgi ve belgelerin değişimini içeren karmaşık iş akışları yoluyla sağlanır (Fensel ve Bussler, 2002). Bu nedenle, iş süreci yönetimi (BPM) bu tür hizmetleri çevrimiçi hale getirmeyi kolaylaştırmak için önemli bir konudur. BPM'li bilgi sistemlerini tanıtmakta başarısızlığın yaygındır, çünkü altta yatan iş sürecini veya iş akışını desteklemekte ciddi sıkıntılar vardır. Ayrıca, birlikte çalışabilirlik sorunları, kamu hizmetlerinin çevrimiçi ortama etkin biçimde kaydırılmasını önemli ölçüde etkilemektedir (Barjis, 2008; O'Hara ve Stevens, 2006). Birlikte çalışabilirliğin boyutları arasında şunlar yer almaktadır: iş amaçlarını tanımlamak, BPM modellemesi ve bilgi alışverişi yapmak isteyen ve farklı iç yapı ve süreçlere sahip olabilen kamu kurumlarının işbirliğini ve açık ara yüzlerin yönlerini kapsayan teknik birlikte çalışabilirliği sağlamak; arabağlantı, veri entegrasyonu, sunum ve değişim, erişilebilirlik ve güvenlik hizmetleri (Guijarro, 2009; IDABC, 2004).

İş akışı modelleri BPM' i bilgi sistemlerine uygulamak için kullanılabilir (Thom, Lochpe ve Reichert, 2007). Böyle bir uygulama için, üç strateji önerilmiştir (Dennis ve Haley Wixom, 2000). Birincisi; mevcut geleneksel süreçleri otomatik olarak destekleyerek veya değiştirerek, kullanıcıların tarafında verimliliği arttırmayı hedefleyen İş Süreçleri Otomasyonu (BPA) olanlarıdır. İkincisi ise artımlı değişiklikler yoluyla ancak yeni süreçler veya yeni görevler oluşturmadan süreçleri rötuşlamayı amaçlayan İş Süreç İyileştirme (BPI) yapılarıdır. Son olarak, süreçlerin değerlendirilmesi, ilaveler veya elemelere çevrilen süreçlerin temel ve kritik olarak yeniden düşünülmesine dayanan ve maliyetler bakımından hizmet performansını artırmak için yeni süreçlerin yaratılmasına dayanan İş Süreçlerinin 
Yeniden Yapılandırılması (BPR), hizmet sunumu, kalite ve hiz etkenleridir (De Jager ve Van Reijswoud, 2008). Buna göre, iş süreci yönetimi (BPM) ilkelerini kullanarak devlet süreçlerinin iyileştirilmesine odaklanılmalıdır. Aslında, BPM e-devlet sistemlerinin destek süreçlerinin mükemmelliği sayesinde daha verimli hale getirilmesinde büyük öneme sahip olduğu kabul edilmiştir (Palkovits ve Wimmer, 2003; Walser ve Schaffroth, 2010).

BPM, iş süreçlerini ve ilgili tüm kaynakları anlamak, belgelemek, modellemek, analiz etmek, simüle etmek, yürütmek ve sürekli olarak değiştirmek için yapılandırılmış ve tutarlı bir yöntemdir (Recker ve ark. 2006). Beş aşamayı kapsayan uçtan uca bir yaşam döngüsü sağlar: planla, tasarla, yerleştir, pilotla ve değerlendir. Bununla birlikte, hükümet süreçlerinin iyileştirilmesi açıkça karmaşıktır ve yasal, sosyal, politik ve ekonomik yönlerin çözümünü ve geliştirilmesini gerektirir (Zhang ve Hou, 2011; Barraza ve diğerleri, 2011). İşletme ve hükümet süreçleri arasındaki bu farklılıklar, BPM uygulamalarının ve hükümet süreçleri için ilkelerin kullanılması olarak tanımlanan hükümet süreç yönetiminin (GPM) doğuşuna neden olmuştur.

Öte yandan, BPM ve ortaya çıkan çözümler, özel sektördeki süreçlerin mükemmelliği ile sağladığ 1 büyük yararları göstermiştir (Jeston ve Nelis, 2008). BPM, iş süreçlerini ve ilgili tüm kaynakları anlamak, belgelemek, modellemek, analiz etmek, simüle etmek, yürütmek ve sürekli olarak değiştirmek için yapılandırılmış, tutarlı bir yöntemdir (Recker ve ark. 2006). İş süreçleri için planlamadan değerlendirme ve geliştirmeye kadar çeşitli aşamalardan oluşan bir yaşam döngüsü boyunca yinelemeli bir bakış açısı getirir. Bununla birlikte, bu tür bir çözümü devlet süreçleri için kullanmak doğrudan kabul edilemez: e-iş çözümleri ve kalkınma yaklaşımları doğrudan devlet kurumlarına aktarılamaz (Zhang ve Hou, 2011). Bu, şu tür süreçleri niteleyen unsurlardan kaynaklanmaktadır: yasal yönü (Becker ve ark. 2007), sosyal yönü (Grimsley ve Meehan, 2007), politik yönü (Oates, 2003) ve ekonomik yönü (Ellis, 2004). ).

İşletme ve hükümet süreçleri arasındaki bu farklılıklar, BPM' den yola çıkarak GPM adlı yeni bir düşünceye yol açtı (Scholl, 2003; Zhang ve Hou, 2011). GPM, BPM uygulamalarının ve ilkelerinin devlet süreçleri için kullanımı olarak tanımlanmaktadır. GPM perspektifine göre, devlet süreçleri karakteristik yönlerinden kaynaklanan gerekliliklerle uyum sorununa tabidir (Barraza ve diğerleri, 2011). Dolayısıyla "yasal yön" olarak adlandırılan belirli bir konu üzerine odaklanılmalıdır. Bu, 'yasal gereklilikler' olarak belirtilen kısıtlamaları (kurallar, ön koşullar, vb.) ve süreç modellerinin tanımını (bileşenler, hiyerarşi vb.) içeren yasal metinler setinde tanımlanır (Cherouana ve Mahdaoui, 2015; Khadraoui ve ark. , 2011). Bir literatür taraması, bazı araştırma çalışmalarının bu spesifik bağlam için BPM yaşam döngüsünü yeniden gözden geçirmeye çalıştığını ortaya koymuştur. Şekil 1' de B2B ve $\mathrm{B} 2 \mathrm{G}$ veri alışverişi için basitleştirilmiş platform mimarisi verilmiştir. 


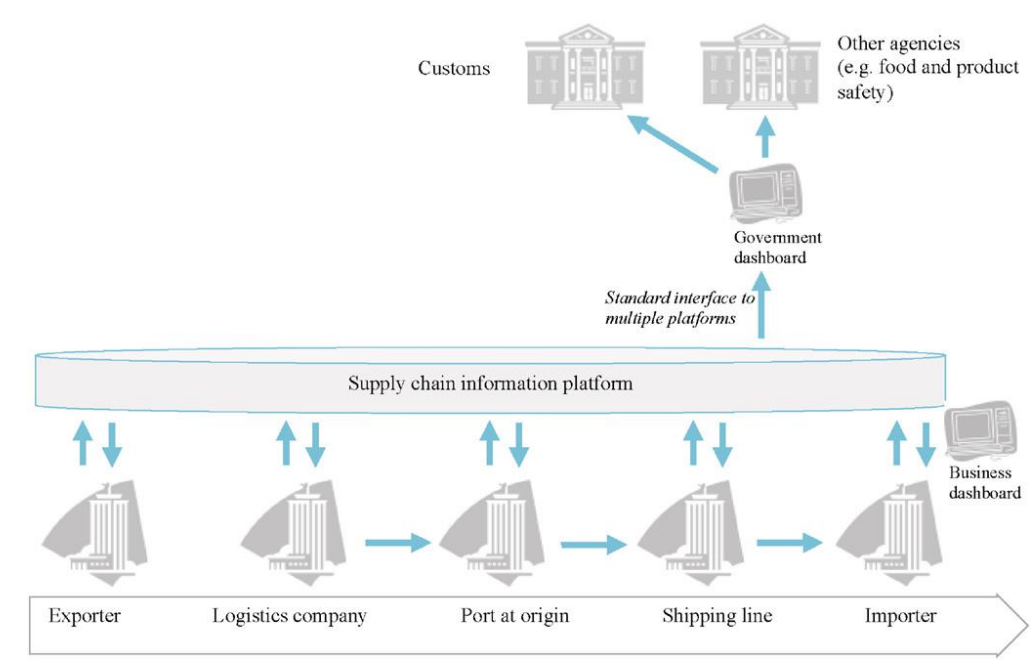

Şekil 1. B2B ve B2G veri alışverişi için basitleştirilmiş platform mimarisi.

\section{3. İş Süreç Yönetimi Notasyonu (BPMN)}

İş süreçleri yönetimine (BPM), iş süreçleri modelleme notasyonundan olduğu gibi ve örnek senaryoların bir gösterimi olarak iş süreci modelleme gösteriminden, hizmet kullanarak tam iş akışı entegrasyonuna sahip BPM sistemlerine kadar entegre araçlarla desteklenen bir yönetim stratejisi (Lee ve Dale, 1998) olarak bakabiliriz. işletme mimarisine entegre edilmiş mimari odakl1. İşletme mimarisi, gelişmiş işletmelerde iş modelinin (değer yaratma, sağlama ve yakalama) uygulanmasında etkili olabilir. BPM'ye olan ilginin artmasına rağmen, BPM'nin iki veya daha fazla ayrı tüzel kişilik arasında koordine edildiği organizasyonel bağlam da dahil olmak üzere başarılı BPM için bağlamın önemine ilişkin literatürde bir boşluk vardır (Cleven ve Diğerleri, 2014; Chesbrough ve Rosenbloom, 2002; Niehaves ve Diğerleri, 2012). Sonuç olarak, genel BPM araştırmalarının, bazı konularda yeni zorluklar yarattığı ve çoğu sanayileşmiş ülkede sektörel işbirliğini zorladığı; örneğin sağlık sektörü gibi yüksek düzeyde uzmanlaşmış bağlamlarda işbirlikçi çabaları nasıl işbirliği edebileceği konusunda belirsizlik mevcuttur (Garmann-Johnsen ve Eikebrokk, 2017).

Dinamik süreçler, alt süreçler ve bunların faaliyetleri (iç içe geçme ve dahil etme), birleşme / ayrılma noktalarının ve tetikleme olaylarının tanımlanması arasındaki yapısal ilişkilerin / bağımlılıkların ifadesini sağlar. Yasal gereklilikler devlet süreçlerinin dinamiklerini tanımlayan kurallar ve kısıtlamaları kapsar. Dolayısıyla, devlet süreçleri için bu husus "yasal özellikler modeli" ile resmileştirilmesi gerekliliği ortadadır. Bu durum, özellik odaklı alan analizi (FODA) prensiplerine dayanmaktadır. FODA, resmi bir semantik (mantık tanımlama aksiyomları) destekleyen bir ağaç olarak belirli bir alanla ilişkili özelliklerin ve özelliklerin açık bir sunumunu sunar. Dinamik süreçler, modelin iş akışı teknolojileri (örneğin, iş akışı ağları, BPMN, vb.) tarafından desteklenen çeşitli çalıştırılabilir modellere ve daha sonra yasal gereksinimlerin devlet çalıştırılabilir modellerine dönüştürülmesine dönüştürülebilir (Cherouana ve Mahdaoui, 2015). Böylece, tasarlanan yasal gereklilikler korunur ve ortaya çıkan modeller yasal yönleriyle uyumludur ve otomatik uygunluk kontrolüne tabi tutulabilir.

Günümüzde, İş Süreci Modeli ve Notasyonu BPMN, iş süreçleri diyagramları için fiili standart haline geldiği söylenebilir. Bununla, iş süreçlerini tasarlayan, yöneten ve gerçekleştiren paydaşlar tarafından doğrudan kullanılması amaçlanmıştır ancak aynı zamanda yaklaşım BPMN diyagramlarının yazılım süreci bileşenlerine çevrilmesine izin verecek kadar 
kesin olmalıdır. BPMN, herhangi bir özel uygulama ortamından bağımsız, kullanımı kolay bir akış çizelgesi benzeri gösterime sahiptir (White, 2004).

İş Süreci Modellemesi Notasyonu (BPMN), planlı bir iş sürecinin adımlarını baştan sona modelleyen bir akış şeması yöntemidir. İş Süreci Yönetimi'nin anahtarı, bir süreci tamamlamak için gereken iş faaliyetlerinin ve bilgi akışlarının detaylı bir dizilimini görsel olarak gösterir. Amacı, verimliliği iyileştirme, yeni koşulları hesaba katma veya rekabet avantajı elde etme yollarını modellemektir. Metot son birkaç yıldır daha da standardizasyona girmektedir ve yazılım tasarımında kullanılan Birleşik Modelleme Dili'nden (UML) farklıdır (Todd McKinnon, C. a.-F. (2019, 09 12). https://www.lucidchart.com/pages/bpmn. lucidchart:).

İş Süreci Modelleme Notasyonu, İş Süreci Yönetim Girişimi (BPMI) tarafindan geliştirilmiştir ve bir dizi revizyondan geçmiştir. 2005 yılında, bu grup, girişimi devralan Nesne Yönetim Grubu (OMG) ile birleşmiştir. 2011 yılında, OMG BPMN 2.0'1 piyasaya sürmüş ve yöntemin ismini İş Süreci Modeli ve Notasyonu olarak değiştirmiştir. İş Süreçleri Diyagramları için daha zengin bir semboller kümesi ve göstergeler kullanarak, iş süreçleri modellemesi için daha ayrıntılı bir standart oluşturulmuştur. BPMN, 2014'ten bu yana, Karar Modeli ve Notasyon standardı adı verilen bir karar akış şeması yöntemiyle de tamamlanmıştır.

BPMN, yüksek düzeyde, adımların anlaşılması kolay görsel sunumuyla anlaşılması için bir iş sürecindeki katılımcılara ve diğer paydaşlara yöneliktir. Daha ilgili bir seviyede, süreci uygulayacak kişileri kesin bir şekilde uygulamaya koymak için yeterli ayrıntıyı vermeyi hedeflemektedir. İster teknik ister teknik olsun olmasın tüm paydaşlar için standart, ortak bir dil sağlar: iş analistleri, süreç katılımcıları, yöneticiler ve teknik geliştiriciler, ayrıca dış ekipler ve danışmanlar. İdeal olarak, iş faaliyetleri sırasına yeterli ayrıntı ve netlik sağlayarak süreç niyeti ile uygulama arasındaki boşluğu kapatır. Sekil 2' de Örnek BPMN Diyagramı verilmiştir.

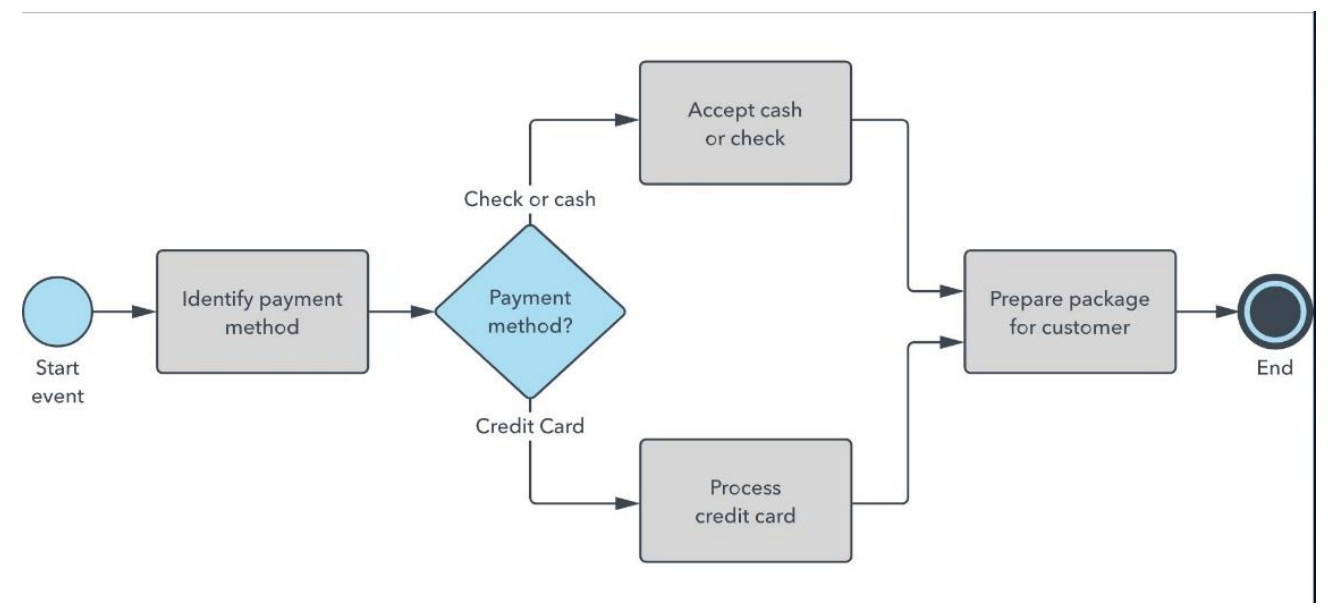

Sekil 2. Örnek BPMN Diyagram (Todd McKinnon, C. a.-F. (2019, 09 12). https://www.lucidchart.com/pages/bpmn. lucidchart:)

Diyagramlama, anlatılan metnin olabileceğinden çok daha kolay olabilir. Yüksek kaliteli sonuç veren verimli bir süreç hedefine ulaşmak için daha kolay iletişim ve işbirliğine olanak tanır. Ayrıca, çeşitli işlemleri yürütmek için gereken XML (Genişletilebilir İ̧saretleme Dili) belgelerine yol açan iletişimi sağlar. Bir ana XML standardı, Web Servisleri için İş Süreci Yürütme Dili anlamına gelen BPEL veya BEPEL4WS olarak adlandırılmaktadır (Wohed ve Diğerleri, 2006)

$\mathrm{BPMN}$, iş süreci diyagramları için dört unsur türünü vardır: 


\section{Aklş nesneleri:}

Olaylar: Bir işlemi başlatan, değiştiren veya tamamlayan bir tetikleyici. Etkinlik türleri arasında mesaj, zamanlayıcı, hata, telafi, sinyal, iptal, yükseltme, bağlantı ve diğerleri sayılabilir. Olay türüne göre başka semboller içeren daireler ile gösterilirler. İşlevlerine bağglı olarak "atma" veya "yakalama" olarak sinıflandırılırlar.

Aktivite: Bir kişi veya sistem tarafından gerçekleştirilen belirli bir faaliyet veya görev . Köşeleri yuvarlatılmış bir dikdörtgenle gösterilir. Alt işlemler, döngüler, tazminatlar ve çoklu durumlar ile daha ayrıntılı hale gelebilirler .

Ağ geçidi: Koşullara veya olaylara göre yolu ayarlayabilen karar noktası. Elmas olarak gösterilirler. Özel veya kapsayıcı, paralel, karmaşık veya verilere veya olaylara dayanarak olabilirler.

\section{Bağlantılı nesneler:}

Dizi akışı: Gerçekleştirilecek faaliyetlerin sırasını gösterir. Bir ok ile düz bir çizgi olarak gösterilir. Koşullu bir akış veya varsayılan bir akış gösterebilir.

Mesaj akışı: "Havuzlar" veya departmanlar gibi organizasyon sınırları boyunca akan mesajları gösterir. Bir havuzdaki etkinlikleri veya etkinlikleri birbirine bağlamamalıdır. Başlangiçta bir daire ve sonunda bir ok ile kesikli bir çizgi ile temsil edilir.

Ortaklık: Noktalı bir çizgi ile gösterilen, bir eser veya metni bir olaya, etkinliğe veya ağ geçidine ilişkilendirir.

\section{Swimlanes: havuz veya şerit:}

Havuz ve yüzmek: Bir havuz bir süreçteki ana katılımcıları temsil eder. Farklı bir havuz farklı bir şirkette veya bölümde olabilir, ancak yine de sürece dahil olabilir. Havuzdaki yüzücüler, sürecin hangi bölümlerinden kimin sorumlu olduğunu tanımlayan belirli bir rol veya katılımcı için etkinlikleri ve akışı gösterir.

Eserler: veri nesnesi, grup, açıklama:

Buluntu: Geliştiricilerin, şemaya gerekli bir ayrıntı düzeyi getirmek için eklediği ek bilgiler. Üç tür artefakt vardır : veri nesnesi, grup veya ek açıllama. Bir veri nesnesi , bir aktivite için hangi verilerin gerekli olduğunu gösterir. Bir grup , faaliyetlerin mantıklı bir gruplandırmasını gösterir ancak diyagramın akışını değiştirmez. Bir açıklama, şemanın bir kısmına daha fazla açıklama sağlar.

\section{4. e-Devlet Mimari Yapılarında Süreç Yönetiminin Yeri}

e-Devlete bakış açısı bazı kamu hizmetlerinin elektronik ortamda sunulması olmamalı, sürdürülebilir ve maliyet-etkin bir e-devlet oluşturulması için sağlam temellere dayanan bütüncül bir e-devlet mimarisi kurgulanması temel öncelik olmalıdır (Helali ve ark., 2011). eDevlet mimarisi bağlamında süreç yönetimi akademik olarak çalışılmış bir konudur. Süreçlerin daha etkin yönetimi ve ihtiyaca göre anlık müdahale edebilme kabiliyeti, yeni kamu yönetimi yaklaşımının esaslı bir unsuru olarak görülmektedir (Schedler ve Proeller, 2011). Kamu hizmetlerine ilişkin süreçlerin tanımlanması, kurumlar arası işbirliklerine ilişkin bir sistematik geliştirilmesi ve bütün bunların bir teknoloji altyapısına dönüşümünün sağlanması bu süreçteki esas meseledir. Buna ilişkin akademik alanda olduğu kadar uygulamada da bazı çözümler geliştirilmiştir.

İsviçre' de kamu hizmetleri için BPMN uyumlu bir süreç yönetim döngüsü işletilmekte olup www.ech.ch internet adresi üzerinden bilgilendirme yapılmaktadır. Bu adres kamu girişimiyle oluşturulmuş ancak bağımsız yapıdaki bir birlik tarafından yönetilmektedir. BPM 
Başlangıç Kiti (BPM Starter Kit) adında ücretsiz bir yazılımla da desteklenen yapıda süreçlerin dokümantasyonu yapılabilmektedir. Süreç odaklı hizmet sunumunun başarılı olabilmesi için paydaşların sundukları teknolojik hizmetlere süreç odaklı bakabilmelerinin gerekli olduğu vurgulanmaktadır, ki bu aslında bilişim uzmanlığında kültür değişimi anlamına gelmektedir (Schedler ve Proeller, 2011).

İsviçre örneğinde hizmet envanteri için eCH-0070, hizmet ve süreç tanımlamaları için eCH-0073 ve süreç modelleri ile tecrübe paylaşımına ilişkin olarak eCH-0096 başta olmak üzere çeşitli standartlar oluşturulmuş olup bütün bu unsurlar daha genel kapsamlı e-devlet çerçevesinin bir parçası olarak ele alınmaktadır (Schedler ve Proeller, 2011).

Gouscos, Drossos ve Marias (2005) tarafindan önerilen bir mobil devlet mimarisinde süreç yönetimi bir bileşen olarak ele alınmıştır. Benzer şekilde, Sandoz (2009) tarafından önerilen e-devlet mimari modelinde de süreç motoru bileşeni yer almakta olup bütün süreçlerin bu bileșen aracılığıyla yürütülmesi önerilmektedir. $\mathrm{Bu}$ tür araştırmalar yeni olmamakla birlikte BPMN standardının bu amaçla kullanımı ve hukuki süreçlerin kamusal süreçlere entegrasyonuna yönelik bütüncül bir çalışma, bilindiği kadarıyla, gerçekleştirilmemiştir.

Özel sektörün aksine, kamu sektöründe süreçler mevzuat altyapısı ile bağlantılı olduğundan (Walser ve Schaffroth, 2010), süreç yönetimine ilişkin geliştirilecek bir mekanizmada mevzuat yönetimi unsurunun da yer alması yerinde olacaktır. Süreç yönetiminin mevzuat ile ilişkilendirilmiş olması olası mevzuat değişikliklerinin sürece yansımalarının anında tespit edilmesini sağlayacağı gibi mevzuatın pratik hayata yansımadaki etkinliğinin de otomatik araçlarla gözlenebilmesini sağlayacaktır. Günümüze dek mevzuat kaynaklarının makineler tarafından yorumlanabilmesini sağlayacak farklı amaçlarla çok sayıda yapısal dil ve standart geliştirilmiştir (Lupo ve ark., 2007). Yakın gelecekte hukuk uzmanlığının büyük oranda bilgi sistemleri tarafından yürütülme potansiyeline sahip olduğu son zamanlarda sıklıkla dile getirilmeye başlanmıştır (Ersoy, 2019). Bu hususlar birlikte düşünüldüğünde, kamu süreçlerinin hukuki yapı ile uyumlaştırılmaya başlanmasının ulusal öncelikler arasında değerlendirilmesi gerekmektedir.

Kamu hizmetlerinin sunumu için münferit e-devlet projelerinin e-devlet kapısından sunumu ilk aşamada yeterli olmakla birlikte bu adımın ötesine geçilerek kamu hizmetlerinin süreç odaklı olarak yeniden ele alınması ve bütüncül bir mimari tasarıma geçilmesi elzemdir. Aksi halde artan idame maliyetleri ile baş edilemeyecek ve çevik devlet yaklaşımının gerektirdiği dinamiklik ihtiyacı karşılanamayacaktır. Ele alınan kamu hizmet süreçlerinde ortak hizmetler için ortak bir süreç tasarımı oluşturulması da önem taşımaktadır. Bütün bu unsurlar öncelikle akademik olarak çalışılmalı, belirli bir plan dâhilinde hayata geçirilmelidir.

\section{Sonuçlar}

Kamu sektörü karar vericileri BPM için dinamik yetenekler oluşturma ihtiyacını anlamalıdırlar. Bununla birlikte, bu yetenek geliştirme sadece yakınsama teorisi temelli olgunluk modelleri ile değil, aynı zamanda dinamik yetenek literatüründe (ayrışma teorisi) önerilen örgütsel pozisyonlar tarafından yönlendirilmelidir. Dolayısıyla kamu sektöründe BPM yeteneklerini anlama konusuna odaklanılmalıdır. Dinamik yetenek teorisi ve yetenek gelişimi genel olarak özel sektörde iyi uygulanabiliyorsa, bu teorinin kamu sektörü örgütlerini incelemek için de uygulanması gerekliliği ortaya çıkmaktadır (Niehaves, Plattfaut, ve Becker, 2013).

Araştırmaların sonuçları göstermiştir ki; bir BPMN işlemi, grafiksel bir diyagram vasıtasıyla görselleştirilir ve davranışı, işlem akışını geçen belirteçlerle gösterilebilir. BPMN'de bir belirteç, gerçekleştirildiğinde proses davranışını tanımlamak için yardımcı 
olarak kullanılan teorik bir kavramdır. Bir işlem öğesinin davranışı, belirteç işlemin yapısını 'geçtiğinde' bir belirteçle nasıl etkileşime girdiğini tanımlayarak tanımlanabilir. Hareketli akış elemanının semantiğine bağlı olarak, bir süreçteki belirteçlerin sayısı sürekli üretilip tüketildiklerinden değişebilir. Örnek olarak, bir başlangıç olayı bir belirteç oluşturur, bir bitiş olayı ise bu belirteci tüketir (Model, B. P. Notation (BPMN) V2. 0.2, OMG.).

Bununla birlikte, istisna akışlarının varlığı, özellikle de süresi bizim kalıp kalitemizle kısıtlanan göreve bağlı kesintisiz etkinliklerden kaynaklananlar, BPMN her istisna akışının sona ermesini tavsiye ettiğinden, genel sürecin hem iyi yapılandırılmış hem de yapısal sağlamlığından ödün vermez. Kendi nihai olayı olan bir sınır olayından kaynaklanır. $\mathrm{Bu}$ nedenle, süreç modellerimizdeki istisna akışları bu yapısal özellikleri karşılamamaktadır. Bununla birlikte, BPMN süreç yapısal özelliklerinden tasarlanan süreç modellerinin esnek ve modüler olduğunu ve yeni yapılandırılmış süreç dalları, bölgeler veya alt süreçler eklenerek kolayca genişletilebileceğini bilinmelidir (Combi, Oliboni, ve Zerbato, 2019).

\section{Tartışma ve Öneriler}

Platformlar kamu-özel sektör işbirliği için dış dönüşüm ile kapsayıcı bir araç oluşturur. Bunlar hem caziptir çünkü hem yatay hem de etkileşime giren kuruluşlar arasında ve dikey olarak (birden fazla devlet kurumu için paylaşılan hizmetler) entegre olurlar, hem iş hem de devlet kurumları için fayda sağlar. Platform yönetişim hakları hem kamu hem de özel sektöre verilebilir. Bununla birlikte, devlet kurumları kamu değerlerini güvence altına almak için göreceli olarak yüksek bir kontrol seviyesine sahiptir ve aynı zamanda işletmeler bu kamu değerlerini güvenceye almaktan ve inovasyonu teşvik etmekten sorumlu hale gelirler. Özerklik ve kontrol arasında bir denge kurmak, kamu sektörünün çıkarlarına uygun iş modelleri bulmak ve standartları ve altyapı bileşenlerini seçmek ve benimsemek için ortak bir süreç oluşturmak, dönüşümün çalışmasını sağlamak için hayati unsurlardır. Bir yönetişim, dış gelişmelerden yararlanarak ve özel sektör yeniliklerinden yararlanarak dişarıdan dönüşümü mümkün kılarak işletmelerin ve toplumun çıkarlarını birleştirebilir. Bununla birlikte, platformlar arası dönüşüm gerçekleşmeden önce bazı zorlukların ele alınması gerekmektedir. $\mathrm{Bu}$ zorluklar, işletmeler için bir platformun birlikte geliştirilmesi ve kullanılması için doğru teşviklerin verilmesinden, veri tanımlarının ve sistem arayüzlerinin standartlaştırılmasına, kamu-özel yönetim yapısında karar vericilerin tahsis edilmesine kadar uzanmaktadır. Gündem belirleme, iş modeli oluşturma, yeniden dağıtma, seviye oyun alanı oluşturma, standardizasyon ve son olarak, çare, sübvansiyon gibi politika araçları aracılığıyla devlet kurumları, platformların geliştirilmesi ve benimsenmesi konusunda işbirliğine yardımcı olabilirler. Bununla birlikte, bu rolü yerine getirmek, altyapı bileşenlerinin kurumlar arası süreç modelleri, veri elemanları ve mesaj özellikleri, hizmet odaklı mimariler ve bilgi güvenliği konularını içerdiği için kolay bir iş olmayan bilgi altyapısı bileşenlerinin ve potansiyel araçların politika yapıcılar tarafından derinlemesine anlaşılmasını gerektirir. Sadece eldeki durumu hedef alan araçların bir kombinasyonu etkili olabilir. Önemli olan tüm tarafların potansiyel avantajları bilmesi ve kabul etmesidir. Ancak o zaman dönüşüm için dışiç yaklaşım alınabilir.

Bu zorluklar 1şı̆̆ında, kamu-özel yönetim yapısına çok az dikkat edilmesine karşı bilgi altyapısına çok fazla dikkat çekmek, dönüşüm çabalarını engelleyecektir. Kamu-özel yönetim yapıs1, dönüşümden etkilenecek paydaşlar tarafindan belirlenip kabul edildikten sonra, bilgi altyapısı, platformun etkin olduğu dönüşüm girişimlerinde nispeten hızlı bir şekilde gelişebilir.

GPM perspektifine göre, devlet süreçleri karakteristik özelliklerinden kaynaklanan gerekliliklerle uyum sorununa tabidir (Barraza ve diğerleri, 2011). Aslında, ticari faaliyetlerin ve birikmiş deneyimin bir sonucu olan iş süreçlerinin aksine, devlet süreçleri, uygulama ve 
paydaş memnuniyetinin kanıtladığı sıkı mevzuatın bir sonucudur (Khadraoui ve ark. 2009). Başka bir deyişle, devlet süreçlerinin mimarisi, burada "yasal gereklilikler" olarak belirtilen belirli kısıtlamalara (kurallar, ön koşullar vb.) ve belirli modellere (bileșenler, hiyerarşi vb.) uymalıdır. Yasal gereklilikler genellikle devlet kurumlarıyla ilişkili bir dizi yasal metin olarak tanımlanır ve verilen bir hükümet sürecinin tasarım aşamasında yeterince dikkate alınmaz. Bununla birlikte, bu bağlamdaki mevcut katkılar, yasal tasarımların çıkarılması ve açık tasarım ve uygulamalarına izin veren anlamsal çözümler kullanılarak bilgisayarlı olanlara çevrilmesi için yöntemlerin eksikliği konusunda hala çok sınırlıdır. Bunların sonucunda, GPM yaşam döngüsünün tasarım aşamasını çok ciddi bir şekilde ele alınmalı ve hükümet süreçlerini katı yasal yönlerine uygun olarak tasarlamak üzere evrimsel bir çerçeve geliştirilmelidir. Makalede ele alınan konunun önerilerini kamu yönetişimcilerine iletmek gerekliliği ortadadır.

Kamu kurumlarında süreç odaklı bakış açısını temin edecek birimler oluşturularak münferit hizmet odaklı yaklaşımdan bütüncül hizmet odaklı yaklaşıma geçiş sağlanmalıdır. $\mathrm{Bu}$ geçişte, süreç modelleme yaklaşımının teknoloji ile bütünleştirilebileceği teknik altyap1 mevcuttur. BPMN kullanımı ile kamu genelinde süreçlerin hiyerarşik bir şekilde tanımlanarak merkezi ve yerel seviyelerde otomatik bir şekilde işletilmesi mümkündür. Bu teknolojinin geçmişten beri arzu edilen çok katmanlı performans takibine de ortam sağlayacağı hatırda tutulmalidir.

\section{Kaynakça}

Barjis, J. (2008). The importance of business process modeling in software systems design. Science of Computer Programming 71 (1), 73-87.

Barraza, S., Francisco, M. and Figueras, Y. (2011) 'Study of continuous process improvement (CPI) regarding public management', Revue Internationale d'administration publique et développement, Vol. 53, No. 39, pp.75-100.

Başbakanlık (1999), “Türkiye Ulusal Bilgi Sistemi”, T.C. Başbakanlık, Ankara.

Başbakanlık (2001), “e-Türkiye Raporu”, T.C. Başbakanlık İdareyi Geliştirme Başkanlığı, Ankara.

Bellman, B., \& Rausch, F. (2004). Enterprise architecture for egovernment. Proc. of EGOV 2004 Conference (48-56). Berlin: Springer (Lecture Notes in Computer Science 3183).

Borins, S. (2014). The Persistence of innovation in government. Cambridge: Brookings Insttution Press with Ash Center for Democratic Governance and Innovation.

Cherouana, A. and Mahdaoui, L. (2015) 'Supporting legal requirements in the design of publicprocesses', 5th IFIP International Conference on Computer Science and its Applications (CIIA'2015), IFIP Advances in Information and Communication Technology, Vol. 456, pp.231-242.

Cherouana, A. and Mahdaoui, L. (2015) 'Supporting legal requirements in the design of publicprocesses', 5th IFIP International Conference on Computer Science and its Applications (CIIA'2015), IFIP Advances in Information and Communication Technology, Vol. 456, pp.231-242.

Cherouana, A., Mahdaoui, L., \& Khadraoui, A. (2017). BPM-based framework for egovernment processes improvement: legal requirements integration. International Journal of Intelligent Information and Database Systems, 10(1-2), 21-50. 
Chesbrough H, Rosenbloom RS. (2002). The role of the business model in capturing value from innovation: evidence from Xerox Corporation's technology spin-off companies. Ind Corp Change;11(3):529-55.

Ciaghi, A., Weldemariam, K., Villafiorita, A., Kessler, F.B. (2011), "Law Modeling with Ontological Support and BPMN: a Case Study", The Second International Conference on Technical and Legal Aspects of the e-Society (CYBERLAWS 2011), 2011.

Cleven AK, Winter R, Wortmann F, Mettler T. (2014). Process management in hospitals: an empirically grounded maturity model. Bus Res;7(2):191-216.

Combi, C., Oliboni, B., \& Zerbato, F. (2019). A modular approach to the specification and management of time duration constraints in BPMN. Information Systems, 84, 111144.

Çağlar, Ersoy, (2019), "Robotlar, Yapay Zekâ ve Hukuk”, Onikilevha Yay.,4.basım, İstanbul 2019, s. 81-82.

De Jager, A., Van Reijswoud, V., 2008. E-Governance in the developing world in action: the case of DistrictNet in Uganda. Special Issue: E-Governance and Community Informatics. The Journal of Community Informatics 4 (2).

Dennis, A., Haley Wixom, B., 2000. Systems Analysis and Design: An Applied Approach. Wiley, New York.

Fensel, D., Bussler, C., 2002. The web service modeling framework WSMF. Electronic Commerce Research \& Applications 1 (2), 113-137.

Garmann-Johnsen, N. F., \& Eikebrokk, T. R. (2017). Dynamic capabilities in e-health innovation: Implications for policies. Health Policy and Technology, 6(3), 292-301.

Gouscos, D., Drossos, D., Marias, G.: A Proposed Architecture For Mobile Government Transactions. In: Proceedings of Euro mGov 2005, 1st European Mobile Government Conference, Brighton, The United Kingdom (2005).

Guijarro, L. (2007). Interoperability frameworks and enterprise architectures in e-government initiatives in Europe and the United States. Government Information Quarterly, 24(1), 89-101. doi:10.1016/j.giq.2006.05.003

Guijarro, L., 2009. Semantic interoperability in eGovernment initiatives. Computer Standards \& Interfaces, 31174-31180.

Helali, R., Achour, I., Jilani, L.L., Ghezala, H.B. (2011), "A Study of e-Government Architectures”, MCETECH 2011, LNBIP 78, pp. 158-172, 2011.

IDABC, Enterprise and Industry DG., 2004. European interoperability framework for panEuropean egovernment services, version 1.0, Brussels.

Janowski, T. (2015). Digital government evolution: From transformation to contextualization. Government Information Quarterly, 32, 221-236.

Janssen, M., \& Estevez, E. (2013). Lean government and platform-based governance-Doing more with less. Government Information Quarterly, 30(Suppl. 1), S1-S8.

Kalkınma Bakanlığı (2012), “e-Dönüşüm Türkiye Projesi Birlikte Çalışabilirlik Esasları Rehberi”, Sürüm 2.1, Kalkınma Bakanlı̆̆ı, Bilgi Toplumu Dairesi, Mayıs 2012, Ankara. 
Khadraoui, A., Leonard, M., Thi, T.T.P. and Helfert, M. (2009) 'A framework for compliance of legacy information systems with legal aspect', AIS Transactions on Enterprise Systems Journal, Vol. 7, No. 1, pp.15-26, ISSN 1867-7134, GITO mbH.

Khadraoui, A., Opprecht, W., Aïdonidis, C. and Léonard, M. (2011) 'Laws-based ontology for eadministration', Practical Studies in e-Government, Springer books.

Klievink, B., Bharosa, N., \& Tan, Y. H. (2016). The collaborative realization of public values and business goals: Governance and infrastructure of public-private information platforms. Government Information Quarterly, 33(1), 67-79.

Lee R, Dale B. (1998). Business process management: a review and evaluation. Bus Process Manag J;4(3):214-25.

Lisboa, Ana \& Soares, Delfina. (2014). E-government Interoperability Frameworks: A Worldwide Inventory. Procedia Technology. 16. 10.1016/j.protcy.2014.10.012.

C. Lupo, F. Vitali, E. Francesconi, M. Palmirani, R. Winkels, E. de Maat, A. Boer, and P. Mascellani, "Deliverable 3.1: General XML format (s) for legal Sources," 2007.

Model, B. P. Notation (BPMN) V2. 0.2, OMG.

Niehaves B, Plattfaut R, Becker J. (2012).Business process governance: a comparative study of Germany and Japan. Bus Process Manag J;18(2):347-71.

Niehaves, B., Plattfaut, R., \& Becker, J. (2013). Business process management capabilities in local governments: A multi-method study. Government Information Quarterly, 30(3), 217-225.

Ntaliani, M., Costopoulou, C., Karetsos, S., Tambouris, E., \& Tarabanis, K. (2010). Agricultural e-government services: An implementation framework and case study. Computers and Electronics in Agriculture, 70(2), 337-347.

O’Hara, K., Stevens, D., 2006. Democracy, ideology and process re-engineering: realizing the benefits of e-government in Singapore. In: Huai, J., Shen, V., Tan, C.J.(Eds.), Proceedings of Workshop on e-Government: Barriers and Opportunities.

Palkovits, S. and Wimmer, M.A. (2003) 'Processes in e-government - a holistic framework formodelling electronic public services', Second International Conference EGOV 2003, 1-5 September, Prague, Czech Republic.

Pardo, T.A., Burke, G.B. (2009), "IT Governance Capability: Laying the Foundation for Government Interoperability”, University of Albany, SUNY, Center for Technology in Government, Albany, NY.

Pollitt, C., \& Bouckaert, G. (2004). Public management reform: A comparative analysis (2nd ed.). Oxford: Oxford University Press.

Recker, J., Indulska, M., Rosemann, M. and Green, P. (2006) 'How good is BPMN really? Insightsfrom theory and practice', 14th European Conference on Information System (ECIS 2006), Gothenburg, Sweden.

Sandoz, A.: Design Principles for E-Government Architectures. In: E-Technologies: Innovation in an Open World. Lecture Notes in Business Information Processing., vol. 26, pp. 240-245. Springer, Heidelberg (2009).

Schedler, K., Proeller, I. (2011), "New Public Management”, Haupt/UTB, 2006, Stuttgart, Germany. 
Scholl, H.J. (2003) 'E-government: a special case of ICT-enabled business process change', Proceedings of the 36th Annual Hawaii International Conference, p.12.

Shin, D.-H (2007), 'A critique of Korean National Information Strategy: Case of National Information Infrastructures', Government Information Quarterly, 24, pp. 624-645.

Thom, L., Lochpe, C., Reichert, M., 2007. Workflow patterns for business Process modeling. In: Proceedings of Workshops and Doctoral Consortium of the 19th International Conference on Advanced Information Systems Engineering-CAiSE 2007, Trondheim, Norway. Tapir Academic Press, ISBN 978-82-519-2245-6, pp. 349-358.

Todd McKinnon, C. a.-F. (2019, 09 12). https://www.lucidchart.com/pages/bpmn. lucidchart:

Todd McKinnon, C. a.-F. (2019, 09 12). https://www.lucidchart.com/pages/bpmn. lucidchart: https://www.lucidchart.com/pages/home adresinden alındı.

U.K. Service Manual (2019), “GOV.UK Service Manual”, (çevrimiçi) https://www.gov.uk/service-manual, son erişim: 18 Aralık 2019.

Van Veenstra, A.F., Klievink, B., \& Janssen, M. (2011). Barriers and impediments to transformational government: Insights from literature and practice. Electronic Government, An International Journal, 8(2/3), 226-241.

Walser, K. and Schaffroth, M. (2010) 'BPM and BPMN as integrating concepts in egovernment - the Swiss e-government BPM ecosystem', Second International Conference, S-BPM ONE 2010, Karlsruhe, Germany.

Weerakkody, V., \& Dhillon, G. (2008). Moving from e-government to t-government: A study of process re-engineering challenges in a UK local authority perspective. International Journal of Electronic Government Research, 4(4), 1-16.

White, S. A. (2004). Process modeling notations and workflow patterns. Workflow handbook, 265-294.

Wohed, P., van der Aalst, W. M., Dumas, M., ter Hofstede, A. H., \& Russell, N. (2006, September). On the suitability of BPMN for business process modelling. In International conference on business process management (pp. 161-176). Springer, Berlin, Heidelberg.

Zhang, N. and Hou, X. (2011) 'Government process management under electronic government andits application', International Conference on E-Business and EGovernment (ICEE), pp.1-4. 